\title{
Rapid improvement of canine cognitive dysfunction with immunotherapy designed for Alzheimer's disease
}

Maria Neus Bosch ${ }^{1,2}$, Javier Gimeno-Bayón ${ }^{1,2}$, Manuel J Rodríguez ${ }^{2}$, Marco Pugliese ${ }^{2}$, and Nicole Mahy ${ }^{2}$

1. Medivet Pharma SL, Masies de Roda, Barcelona, Spain

2. Unitat de Bioquímica i Biologia Molecular, Facultat de Medicina, Institut d'Investigacions Biomèdiques August Pi i Sunyer (IDIBAPS), Universitat de Barcelona and Centro de Investigación Biomédica en Red sobre Enfermedades Neurodegenerativas (CIBERNED), Barcelona, Spain.

Author for correspondence: Dr. Maria Neus Bosch

$$
\begin{aligned}
& \text { Unitat de Bioquímica i Biologia Molecular } \\
& \text { Facultat de Medicina, UB } \\
& \text { c/ Casanova } 143 \\
& \text { E-08036 Barcelona, SPAIN } \\
& \text { Phone: +3493 } 4024525 \\
& \text { FAX: + } 34934035882 \\
& \text { E-mail: neusbosch@ub.edu }
\end{aligned}
$$

Running headline: $A \beta$ immunotherapy ameliorates dog CDS 


\section{ABSTRACT:}

Immunotherapy against amyloid-beta $(A \beta)$ may improve rodent cognitive function by reducing amyloid neuropathology and is being validated in clinical trials with positive preliminary results. However, for a complete understanding of the direct and long-term immunization responses in the aged patient, and also to avoid significant side effects, several key aspects remain to be clarified. Thus, to investigate brain $A \beta$ clearance and Th2 responses in the elderly, and the reverse inflammatory events not found in the immunized rodent, better Alzheimer's disease (AD) models are required. In the aged familiar canine with a cognitive dysfunction syndrome (CDS) we describe the rapid effectiveness and the full safety profile of a new active vaccine candidate for human AD prevention and treatment. In these aged animals, besides a weak immune system, the antibody response activated a coordinated central and peripheral $A \beta$ clearance, that rapidly improved their cognitive function in absence of any side effects. Our results also confirm the interest to use familiar dogs to develop innovative and reliable therapies for AD.

\section{Keywords}

$A \beta$, Alzheimer's disease, Amyloid vaccine, Canine cognitive dysfunction syndrome, Immunotherapy, Dog. 


\section{INTRODUCTION}

Alzheimer's disease is characterized by the presence of intracellular neurofibrillary tangles and extracellular $A \beta$ plaques, with $A \beta$ monomers and oligomers resulting from the amyloid precursor protein (APP) processing [1]. In the AD amyloid hypothesis, the extracellular accumulation of soluble $A \beta$ peptide leads to CNS formation of soluble oligomers, fibrils and amyloid plaques, and the distribution between brain and blood compartments, reflects the imbalance between $A \beta$ production and clearance [2]. The $A \beta$ fibril formation is currently considered a dynamic and reversible process, as $A \beta$ fibrils are continuously dissolving and reforming [3]. Because $A D$ stage severity correlates more with soluble $A \beta$ brain levels than with $A \beta$ plaque abundance $[2,4,5]$, the amyloid monomers and oligomers are considered to be more toxic $[1,6]$.

Blockade of the $A D$ course at early phases through different immunological anti-A $\beta$ strategies to interfere the amyloid peptide homeostasis have given promising results. For example, active immunization targeting $A \beta$ peptide in $A D$ Tg mice has demonstrated striking reductions in $A \beta$ deposition and reduction of behavioral impairments [7-9], and the same was observed in human beings [10]. However, significant questions remain to be answered for a full understanding of the direct and long-term immunization responses, and to avoid significant side effects in trials conducted with human patients. Thus, the development of new active vaccines inducing both $A \beta$ clearance and only Th2 responses in good AD models remain key issues to be solved $[11,12]$.

Dog with cognitive dysfunction syndrome (CDS) is considered a suitable model to address these innovative therapies [13], because it spontaneously expresses several markers associated with the underlying pathology of sporadic AD. Control aged dog (over 7-8 years) is also considered quite unique to elucidate the amyloid hypothesis, since its CNS A $\beta$ peptide accumulation is responsible for neuronal dysfunction and deregulation of the same specific cortical subsets of interneurons described in the aged 
human [14-17]. In addition, these aged animals also bring multiple druggable targets for the identification of novel disease-modifying agents to interfere natural $A \beta$ production, aggregation, clearance or the associated neurotoxic effects $[18,19]$.

Compared to the aged housed dog, some familiar dogs develop geriatric behavioral changes that give rise to a specific CDS, also known as canine counterpart of senile dementia of the Alzheimer's type. Because of their many common hallmarks, CDS is presently considered a model of choice for Mild Cognitive Impairment $(\mathrm{MCl})$ and $A D$ research $[15,20,21]$, and, in particular, for the development of anti-A $\beta$ immunotherapy $[13,22,23]$. Diagnosed of graded cognitive dysfunctions by practicing neurology veterinarians, these animals are systematically and easily classified into wellcharacterized homogenous groups with no variation due to their breed (including sex, size and genetic background) or familiar life conditions [24-26]. In this study, we took advantage of this familiar model to investigate the effectiveness and safety of new active amyloid vaccines. This study is aimed at increasing our understanding of how immunomodulation supports CNS $A \beta$ clearance, how it relates to cognitive improvement, and how it supports a safe and effective new AD immunotherapy. 


\section{MATERIAL AND METHODS}

\section{Vaccine preparation}

Three different fibrillar $A \beta$ vaccines ( $v 1, v 2$ and $v 3$ ) were initially prepared with $100 \mu \mathrm{g}$ of either $A \beta_{40}$ peptide (>95\% purity; Genscript, NJ, USA) (v1), 100 $\mu$ g $A \beta_{x-40}$ peptide KLH conjugated (>95\% purity; Anaspect, CA, USA) (v2), or $100 \mu \mathrm{g}$ of $2 / 3 \mathrm{~A} \beta_{40}$ combined with $1 / 3$ of the $A \beta_{x-40}$ peptide $K L H$ conjugated (v3). $A \beta_{40}$ and $A \beta_{x-40}$ peptides were initially dissolved with dimethyl sulfoxide (DMSO) $(1 \mathrm{mg} / \mathrm{ml})$, aliquoted and stored at $-20^{\circ} \mathrm{C}$. Once thawed, each solution was mixed with $1 \mathrm{mg}$ of alum hydroxide suspension (Sigma, Spain). After overnight (ON) incubation at $4^{\circ} \mathrm{C}$, a saline solution was added up to a volume of $1.5 \mathrm{ml}$, previous to the subcutaneous (s.c.) immunization of the dog. Placebo animals only received a mixture of saline solution + alum hydroxide suspension.

\section{Human samples}

Brain tissue from AD patients, stage II according to the Braak \& Braak scale [27] was obtained from the Neurological Tissue Bank of the Universitat de Barcelona, Barcelona, Spain. $5 \mu \mathrm{m}$ paraffin embedded slices from hippocampus and cerebral cortex were obtained for immunohistochemistry experiments.

\section{Animals}

To select the vaccine of major interest, 6 adult female New Zealand White rabbits weighing between $1.5-2 \mathrm{~kg}$ at the beginning of the study were immunized with one of the 3 vaccines following the protocol selected for dogs. They were kept on a $12 \mathrm{~h}$ light/12 $\mathrm{h}$ dark cycle and housed with free access to food and water.

The safety and immunization studies were performed in 36 dogs (12 housed beagle dogs + 24 familiar dogs). The 12 male housed beagle dogs from Harlan laboratories (Gannat, France), with an age ranging between 2 and 8 years at the beginning of the study, were housed in groups of three in $1.85 \mathrm{~m}$ wide $\times 3 \mathrm{~m}$ large buildings, and were 
daily fed with $340 \mathrm{gr}$ of Hill's canine adult food. The 24 familiar dogs of different breeds, sex and age were classified into control and dogs with graded CDS (Table 1 ) by a veterinarian neurologist.

All the animals were treated according to the European legislation on animal handling and experimentation (86/609/EU) and, with the formal agreement of the owners of the familiar dogs. Procedures were approved by the Ethics Committee of the University of Barcelona, Barcelona, Spain. All efforts were made to minimize animal suffering and to use no more than the number of animals needed to obtain reliable scientific data.

\section{Cognitive evaluation}

The cognitive status of all 24 familiar dogs was evaluated. A validated cognitive test of 9 items adapted from the Mini-Mental State Examination (MMSE) and the Diagnostic and Statistical Manual of Mental Disorders (DSM IV) for AD was used in collaboration with the pet owners (Table 2) [13,21]. Based on the presence of established housetraining habits, disorientation in familiar surroundings, decreased activity, playfulness, vitality, decreased interaction with the owner, and modifications of the sleep/awake cycle, dogs were divided into two groups: Old Control dogs (OC) and CDS dogs. Depending on the dysfunction grade, the CDS group was subdivided into a group with light cognitive deficit (LCD) or severe cognitive deficit (SCD).

\section{Screening study}

For the screening study all the 36 dogs were classified following their age and cognitive status in Adult Control dogs (AC), OC and LCD or SCD (Table 1).

For each dog, a biochemical and hematological profile was regularly performed that also included $A \beta$ levels in blood and Cerebrospinal Fluid (CSF). The albumin coefficient reflecting the Blood-Brain-Barrier (BBB) integrity [28] was also calculated. All animals were also monitored for adverse reactions and the vaccine puncture zone was periodically revised. 


\section{Immunization study}

Following the recommendation of the Ethics Committee, the use of healthy adult and old familiar dogs as control animals for the immunization study had to be avoided as the following 21 dogs were considered sufficient to obtain reliable data: 9 housed beagle dogs as control group and 12 CDS familiar dogs, with the acceptation of their owners, as the Case group (Table 1).

The study was performed over a period of 131 days, with 6 s.c. injections administered during a period of 51 days in the back of the neck (Fig.1). 6 housed beagle dogs were immunized with the $v 3$ vaccine (Immunized $A C$ ) and 9 dogs CDS dogs were immunized (Immunized CDS). The remaining 3 housed adult beagles and 3 familiar dogs were included in the Placebo group (Table 1). Cognitive follow-up of all CDS animals was performed on a double blind basis at days 31,51 and 131 , by the veterinarian and the pet's owner, and blood and CSF parameters were regularly evaluated (Fig.1).

\section{Blood and CSF extraction}

Serum and plasma were obtained after $5 \mathrm{ml}$ blood extraction from the animal jugular vein every 10 days until day 71 , and then at day 131 . Once collected in tubes (BD, NJ, USA) containing EDTA for plasma or clotting gel for serum, blood was centrifuged at 3000 rpm during 15 minutes, aliquoted and kept at $-80^{\circ} \mathrm{C}$ until use. CSF was collected under $10 \mathrm{mg} / \mathrm{kg}$ of sodium thiopental (Thiobarbital, Braun Medical S.A., Spain) intravenous (i.v.) anesthesia. Then, dogs were intubated, and oxygen administered following induction. Monitoring devices were used to control heart rate, blood pressure and blood oxygenation. The dog's coat was clipped and prepared for an aseptic procedure, and CSF collected $(1 \mathrm{ml} / 5 \mathrm{~kg})$ by cisternal puncture into a sterile glass tube. Afterwards, it was divided into $0.5 \mathrm{ml}$ aliquots and quickly stored at $-80^{\circ} \mathrm{C}$ until use. 


\section{Biochemical and hematological analysis}

Biochemical parameters were analyzed by spectrophotometry (DIRUI CS-800, RAL, Barcelona, Spain) and hematological parameters were measured by laminar flow impedance (Procyte DX, Barcelona, Spain) (Table 3). The albumin quotient (Qalb) was calculated as the quotient between the albumin CSF $(\mathrm{mg} / \mathrm{L})$ and blood $(\mathrm{g} / \mathrm{L})$ concentration. CSF albumin was quantified by immunonephelometry (BN2, Siemens, Marburg, Germany) and serum albumin with the colorimetric bromocresol method (ADVIA 1800, Siemens diagnostic, Marburg, Germany).

\section{Anti-A $\beta$ lgG titration}

For the rabbit anti-A $\beta \lg G$ titration, a Maxisorb 96 well plate (Nunc, Langenselbold, Germany) was coated $\mathrm{ON}$ at $4^{\circ} \mathrm{C}$ with $100 \mu \mathrm{l}$ of $\mathrm{A} \beta_{40}$ diluted at $2 \mu \mathrm{g} / \mathrm{ml}$ in $\mathrm{NaHCO}_{3}$. After a wash with $200 \mu \mathrm{l}$ of Phosphate buffer saline $100 \mathrm{mM}, \mathrm{pH} 7.4+0.05 \%$ Tween (PBST), the plate was blocked during $2 \mathrm{~h}$ at room temperature (RT) with PBS-bovine serum albumin (BSA) $5 \% .100 \mu \mathrm{l}$ of rabbit serum from the different time points was diluted 1/100 with PBS-BSA 5\% and added to the wells after 3 washes during $2 \mathrm{~h}$ at RT. In 3 wells, only diluted PBS was added as a background reference. After 4 washes the biotin anti-rabbit IgG (Sigma Aldrich, MO, USA) diluted at 1/20000 was added for $1 \mathrm{~h}$ at RT. Finally, and after 5 washes, extrAvidin peroxidase $1 / 200$ was added for $30 \mathrm{~min}$ and developed with $100 \mu \mathrm{l}$ of $3,3^{\prime}, 5,5^{\prime}$ tetramethylbenzidine (TMB) during $5 \mathrm{~min}$. The reaction was stopped with $100 \mu \mathrm{H}_{2} \mathrm{SO}_{4} 100 \mathrm{mM}$, and the optical density (OD) registered at 450nm (Tecan, Männedorf, Switzerland).

For the dog serum and CSF anti-A $\beta$ IgG titration, a Maxisorb 96 well plate was also used and coated $\mathrm{ON}$ at $4^{\circ} \mathrm{C}$ with $100 \mu \mathrm{l}$ of $\mathrm{A} \beta_{40}$ diluted at $2 \mu \mathrm{g} / \mathrm{ml}$ in $\mathrm{NaHCO}_{3}$. The plate was then washed with $200 \mu$ l of Tris buffer saline $50 \mathrm{mM}+0.05 \%$ Tween pH 7.4 (TTBS) and blocked with TBS-BSA $5 \%$ for $2 \mathrm{~h}$ at RT. After washing, $100 \mu$ of each diluted serum or CSF sample was added in triplicate and incubated for $2 \mathrm{~h}$ at RT. Serum samples were diluted at $1 / 200$ with TBS-BSA $5 \%$ and CSF samples at $1 / 2$ with TBS. 
Samples from each dog were included in the same plate and 3 wells added with TBSBSA $5 \%$ were also used for background. After 5 washes, each well was incubated for 30min at RT with a biotin rabbit anti-dog IgG (Lifespan bioscience, Derio, Spain) diluted with TBA-BSA $5 \%$ at 1/40000. After 6 washes, streptavidin diluted 1/4000 (Invitrogen, Madrid, Spain) was added and the ELISA kit amplification system (Invitrogen, Madrid, Spain) used for 2 min. Reaction was stopped with $\mathrm{H}_{2} \mathrm{SO}_{4} 0.3 \mathrm{M}$ and OD registered at $492 \mathrm{~nm}$. Data from IgG anti-A $\beta$ titration of the different plates were normalized versus background.

\section{Quantification of $A \beta_{40}$ and $A \beta_{42}$ in plasma and CSF}

A specific ELISA kit (IBL international, Hamburg, Germany) was used for the detection of the total $A \beta_{40}$ and $A \beta_{42}$ in plasma and CSF. Following the manufacturer's guidelines, standard curves, controls and calibration were performed. Samples were also diluted $1: 3$ for the measurement of CSF $A \beta_{42}, 1: 25$ for CSF $A \beta_{40}$ and 1:5 for plasma $A \beta_{40}$. After 7 washes with PBS $100 \mathrm{mM}$, pH7.4 containing $0.05 \%$ Tween-1\%BSA, A $\beta$ species were detected with anti- $A \beta$ antibodies and measured at $450 \mathrm{~nm}$.

\section{Immunohistochemistry}

Immunohistochemistry was carried out on paraffin sections of brain tissues from stage II AD patients according to the Braak \& Braak scale. Purified rabbit anti-A $\beta$ antibodies from serum of $\mathrm{v} 1, \mathrm{v} 2$ and $\mathrm{v} 3$ immunized rabbits or purified dog anti-A $\beta$ from immunized $A C$ and immunized CDS dogs or commercial anti-A $\beta$ antibodies (Dako, Glostrup, Denmark) were used as a primary antibody to detect $A \beta$ plaques. Slices were deparaffined and pre-treated in formic acid for $2 \mathrm{~min}$. After endogenous peroxidase inhibition for $30 \mathrm{~min}$, slices were incubated with PBS $100 \mathrm{mM}, \mathrm{pH} 7.4$, containing $0.5 \%$ triton-X100-Normal goat serum 5\%-BSA $5 \%$ as a blocking agent for $2 \mathrm{~h}$ at RT. Purified primary antibodies were diluted with immunobuffer (PBS-5\%-triton-X100-1\%NGS$1 \% \mathrm{BSA}$ ) at a correct concentration, or commercial anti-A $\beta$ antibody diluted at $1 / 100$ were added an incubated $\mathrm{ON}$ at $4^{\circ} \mathrm{C}$. After 3 washes with $\mathrm{PBS}$, samples were 
incubated with 1/4000 diluted biotin rabbit anti-dog IgG (Lifespan bioscience, Derio, Spain) or $1 / 500$ biotin mouse rabbit IgG for $2 h$ at RT. Finally, after 3 washes, slices were incubated for $1 \mathrm{~h}$ with ExtrAvidin peroxidase (1/250) and developed with $0.03 \%$ Diaminobenzidine (DAB) $0.006 \% \mathrm{H}_{2} \mathrm{O}_{2}$ in PBS. Sections were dehydrated and mounted in DPX. Plaques were visualized by optical microscopy (Olympus America Inc., NY, USA) and micrographs were taken at $5 x$ and $40 x$.

\section{Statistical analysis}

Kurtosis and skewness moments were calculated to verify the normal distribution of data. One-way ANOVA was performed to compare CSF and serum parameters between animal groups. To analyze differences in CSF and serum parameters during the treatment, two-way ANOVA was performed with two factors: Time with 5 levels (day 0 , day 31 , day 51 , day 71 and day 131) of serum parameters, or with 3 levels (day 0 , day 51 and day 131) of CSF parameters, and Treatment (Non-treated, Placebo and Treated). When significant two-way interactions were observed, individual comparisons were performed using one-way ANOVAs followed by LSD post-hoc test. To quantify the association between two variables, a Pearson correlation was performed. When normality was not achieved, the values of all groups were compared using Nonparametric analysis. In these cases, Kruskal-Wallis $(\mathrm{KW})$ test followed by MannWhitney test (MW) were used to compare dependent variable groups, and Sperman correlation to quantify the association between two variables. In all cases, $p<0.05$ was considered as significant. Results are expressed as a mean \pm SEM. All analyses were performed with the programs SPSS 15 (IBM España, Madrid, Spain) and STATGRAPHICS (STSC Inc, Rockville, MD, USA). 


\section{RESULTS}

\section{The $\mathbf{3}$ vaccine induces the highest antibody titration in rabbit}

To select the vaccine of major interest, an immunization study with v1, v2 and v3 was initially conducted in rabbits. To this end, 6 animals ( $n=2 /$ group) were immunized with one vaccine following the immunization protocol selected for dogs. Blood samples were also extracted at the same selected time points until day 71 , and anti-A $\beta$ IgG measured. All three vaccines induced immunization, however the v3 composition gave the highest anti-A $\lg$ g titration at day 71 (Fig. 3A). No side effect was detected in any animal.

\section{Dogs with light cognitive deficits have increased levels of plasma protein, platelets and $A \beta$ levels}

When the 24 familiar dogs were evaluated at the beginning of the study (day 0 ) with our cognitive test, CDS was identified in 14 animals that presented light cognitive deficits $(L C D, n=10)$ or severe cognitive deficits $(S C D, n=4)($ Table 2). The remaining 10 animals classified as control were distributed with the 12 housed beagle dogs between the Adult Control group $(A C,<8$ years, $n=14)$ and the Old Control group (OC, $n=8)$.

During the whole study, all 16 biochemical and hematological parameters were found in the normal range in all animals. However, in the CDS group plasma protein levels and platelets was always higher and reticulocyte counts lower $(p=0.004,0.001$ and 0.002, respectively) (Data not shown).

LCD dogs presented the highest $A \beta_{40}$ plasma level $(p=0.029)$ (Fig. $\left.2 A\right)$, and in all groups $A \beta_{42}$ was lower than the plasma detection limit. In CSF, $A \beta_{40}$ levels remained stable with aging and cognitive dysfunction, while $A \beta_{42}$ levels only increased in the LCD dogs $(p=0.018)(F i g .2 B, C)$. The high variability of their CSF $A \beta_{42}$ values were strongly reduced once subdivided into: LCD1 dogs characterized by CSF $A \beta_{40}$ and $A \beta_{42}$ levels 
similar to those of the Control and SCD groups and highest $A \beta_{40}$ plasma values $(p=0.009)($ Fig. $2 A, B, C)$; and LCD2 dogs with the highest CSF $A \beta_{42}$ levels $(p=0.018)$, and $A \beta_{40}$ plasma and CSF levels similar to those of the Control and SCD groups (Fig. 2C). When this new classification was applied to the plasma protein levels and platelet and reticulocyte counts, differences were observed in the LCD1 group $(p=0.009,0.024$ and 0.010 , respectively) that did not correlate with $A \beta_{40}$ or $A \beta_{42}$ plasma and CSF values. Finally, only in controls Qalb positively correlated with age $\left(R^{2}=0.56, p=0.0008\right)$ (Fig. 2D).

\section{Cognitive improvement of $v 3$ immunized CDS dogs is accompanied by an increased plasma/CSF $A \beta$ ratio}

The cognitive test was performed at days $0,31,51$ and 131 in all dogs included in the v3 immunization study. At day 31 the immunized CDS dogs presented a $30 \%$ lower score $(p=0.027)$ (Fig. 3B) that was maintained until day 51. At this day, a greater reduction of the score was observed in SCD dogs $(45 \%, p=0.010)$ than in LCD ones $(25 \%, p=0.043)$. A tendency to decrease was found in placebo animals, probably due to a closer and more frequent owner and veterinarian care. Due to a failing of several owner visits at the end of the study, only two immunized dogs could be evaluated until day 131. Compared to days 51,31 and 0 , both animals gave a lower score (Score values=11 and 9).

To evaluate the molecular response to v3 immunization, all 16 hematological and biochemical blood parameters, as well as the blood and CSF A $\beta$ and anti-A $\beta_{40} \lg G$ levels, were measured during the whole immunization period.

Only the Alkaline Phosphatase (AP) value was not within the normal range in some familiar dogs (Table 3). Higher AP levels at days 71 and $130(p=0.023$ and 0.049 , respectively) were detected in immunized CDS dogs compared to the placebo group, and were probably related to the irregular familiar feeding habits. 
Qalb ratio remained similar in the AC and CDS groups during the whole study (Data not shown).

In the $v 3$ immunized $A C$ dogs, $A \beta_{40}$ plasma levels presented a tendency to increase until day 41. The same tendency, but with a larger variability, was observed until day 51 in the v3 immunized CDS group (Fig. 4A). When compared with placebo, immunized $A C$ dogs presented a similar $A \beta_{40}$ CSF level between day 0 and 131 , while $A \beta_{42}$ value peaked at day $131(p=0.034)$. In the immunized CDS group, $A \beta_{40}$ CSF levels presented a tendency to decrease (Fig. $4 B$ ), and $A \beta_{42}$ levels were lower at day $51(p=0.049)$ (Fig. 4C). When the ratio between plasma and CSF A $\beta$ was obtained, a major tendency to increase was found in the immunized CDS dogs compared to placebo and AC immunized animals (Fig. 4D). When the analysis was performed with the immunized LCD1, the increasing values reached significant differences between LCD1 immunized dogs and Placebo and AC animals at day $51(p=0.0211)$ (Fig. 4H).

Significant plasma and CSF changes of the anti-A $\beta_{40}$ IgG levels were observed in all $\mathrm{v} 3$ immunized dogs during the whole follow-up,. Thus, in the immunized AC group, the anti-A $\beta_{40} \lg G$ serum levels reached a peak at day 31 and remained increased until day 51 when compared to its pre-immune $(p=0.0042)$ and Placebo group values $(p=0.0079)$; at day 131 it returned to baseline value. Anti-A $\beta_{40} \lg G$ serum levels peaked at day 71 in immunized CDS dogs, higher that their pre-immune $(p=0.0078)$ and the Placebo group values $(p=0.0022)$ (Fig. 4E), being back to baseline at day 131. CSF Anti-A $\beta_{40} \lg G$ of immunized $A C$ dogs were increased at day 51 compared to preimmune $(p=0.0042)$ and placebo values $(p=0.0078)$. CDS animals showed a similar tendency, but with lower levels (Fig. 4F). Both AC and CDS groups presented a positive correlation between serum and CSF anti-A $\beta_{40} \lg$ levels $\left(r^{2}=0.53, p=0.0013\right)$ (Fig. 4I). However, only in the immunized CDS group and during the whole study, the anti-A $\beta_{40} \lg G$ and $A \beta_{40}$ plasma ratio was $1 / 25$, with a positive and linear correlation during the whole study $\left(r^{2}=0.362, p=0.0049\right)$ (Fig. $\left.4 G\right)$. 
Anti-A 340 IgG from v1, v2 or v3 immunized rabbits and $v 3$ immunized dogs recognize human amyloid plaques

In cerebral cortex of human with $A D$, immunohistochemistry with plasma anti- $A \beta \lg G$ isolated from the different immunized rabbits and dogs specifically stained amyloid plaques but not vessels. Purified antibodies from serum of $\mathrm{v} 1$ and $\mathrm{v} 3$ immunized rabbits presented a strong immunodetection of diffuse and core amyloid plaques, but the ones from v2 immunized rabbits only detected diffuse plaques (Fig. 5B, C, D). Purified dog anti-A $\beta$ IgG presented a stronger staining of diffuse plaques than of core plaques (Fig. 5F, G).

\section{DISCUSSION}

Our data reinforce the CDS dog as a good natural $A D$ model and fosters immunotherapy for $A \beta$ pathologies, like canine CDS or human AD. Amyloid pathology associated with canine cognitive dysfunction presents a positive correlation between plaque maturation and degree of cognitive dysfunction [24,29]. In this study, CDS familiar dogs were classified based on their cognitive dysfunction degree and age in order to identify specific biomarkers of amyloid homeostasis of help for AD.

Firstly, the higher values of plasmatic proteins and lower reticulocyte number found in the LCD1 group may reflect the oxidative damage and inflammatory processes involved in the first stages of the disease. Initial amyloid deposition, related to oxidative stress and inflammation [17,30], might then be associated with alterations of hematological parameters present in aging and oxidative damage [31]. Secondly, we also found higher plasma levels of $A \beta_{40}$ in the LCD1 group, which would indicate a relationship between plasma $A \beta_{40}$ and cognitive dysfunction. This hypothesis, approached in rodents and dogs with conflicting results [32-34], is difficult to validate due to the $A \beta$ hydrophobic properties and its important binding to plasma proteins, such as albumin, that cause analytical interferences and variability. 
Similarly, although no relationship has been established between $A \beta$ plasma levels and BBB permeability, several studies in human beings, dogs and rodents describe an increased BBB permeability with aging $[35,36]$. However, besides the association between BBB permeability and inflammatory diseases [37-40], no correlation has been established between BBB permeability and cognitive dysfunction [39,41]. Our results evidence that BBB permeability is only increased in aging healthy dogs, and remains stable in CDS dogs, similar to young matched animals, reflecting a lack of BBB alteration associated with cognitive dysfunction.

In fact, our findings reinforce the familiar dog to help decipher the early events of the diffuse $A \beta$ plaque maturation and explain its relationship with human cognitive dysfunction [13]. For example, together with differences in platelet levels in the LCD1 group, a comparison between these dogs and the human $\mathrm{MCl}$ [42], specifically with amnesic $\mathrm{MCl}$, in which the disease progress to $A D$ might bring new advances.

Finally, we found no correlation between CSF $A \beta_{42}$ and cognitive dysfunction, and only higher $A \beta_{42}$ levels in the LCD group that could be used as a marker of early CDS. CSF $A \beta_{42}$ level, a biomarker for $A D$ diagnosis and monitoring correlates negatively with total $A \beta$ load in the brain, and also with cognitive dysfunction stage [43-45]. On the other hand, our CSF results are similar to those described recently in control housed beagles showing that, between the age of 4 and 16 , CSF $A \beta_{40}$ remains constant and $A \beta_{42}$ presents a slight decrease [14]. However, the lack of data regarding $A \beta_{42}$ and $A \beta_{40}$ plasma variation makes difficult a further amyloid homeostasis explanation. Different dynamic [3] and $A \beta$ aggregation progression processes [46-49] may explain these differences with the studies in human beings.

Despite the differences between some CDS and AD biomarkers, we can establish a relationship between canine cognitive dysfunction and age-related amyloid biomarkers. The dog cognitive improvement associated with changes in several biomarkers verifies the potential of our $A \beta$ vaccine for CDS treatment. Our findings also confirm the interest of immunotherapy to stimulate $A \beta$ peptide clearance across the $B B B$ for a rapid and 
safe cognitive benefit in CDS dogs. Thus, as early as 30 days after initial v3 immunization, plasma $A \beta_{40}$ was increased and both CSF $A \beta_{40}$ and $A \beta_{42}$ decreased. This was followed by an increased A $\beta$ plasma/CSF ratio in the LCD1 group at day 51 . In the immunized adult control dogs, plasma $A \beta_{40}$ was also increased but remained constant in CSF. Therefore, an $A \beta_{40}$ plasma/CSF increased ratio would represent a good marker of plasma clearance.

These modifications in plasma $A \beta_{40}$ were accompanied by a 10 -fold increased serum anti-A $\beta_{40} \lg$, with a peak at day 71 in CDS animals and at day 51 in adult control dogs. Only in this last group, anti-A $\beta_{40} \lg G$ was significantly increased in CSF at day 51 , with an abundance of $0.01 \%$ of serum level, whereas in CDS animals, its increase was not significant. Compared to adult control dogs, the reduced immunogenic response in aged dogs, similar to humans [50], explain the delay and lower level of their serum IgG peak, and the discrete IgG presence in CSF. Anyway, the interrelationship of the processes taking place in CSF and blood seems to be similar in all groups of animals, as shown by the related temporal changes of amyloid parameters and IgG levels in both compartments to facilitate $A \beta$ clearance. This is of special importance in view of the concern regarding the efficacy of immunotherapy in elderly patients with also a weak immune system [51].

The plasma anti-A $\beta_{40} \lg G$ and $A \beta_{40}$ ratio of $1 / 25$ was only found in immunized $C D S$ dogs, suggesting the direct formation of antigen-antibody complexes to stimulate the sink effect from CNS to the periphery [52]. A variety of studies performed with different antibodies that recognize $N$ and $C$ terminal $A \beta$ fragments argue for the same mechanism $[53,54]$. Because differences in antibody recognition of the $A \beta$ peptide define its ability to cross the BBB, our v3 vaccine includes a variety of peptides that induce an antibody mixture to interact with the $N$ or $C A \beta$ terminal. So, the $N-A \beta$ antibody recognition will mostly take place at the periphery, forming ag-ab complexes for the sink effect. Meanwhile, both $\mathrm{N}$ - and $\mathrm{C}-\mathrm{A} \beta$ antibody recognition will favor the 
central recognition of $A \beta$ monomers, oligomers and mainly diffuse plaques, due to the maturation affinity process of $B$ cells during the immunization period $[55,56]$.

BBB damage is observed in many neuropathologies like AD and its permeability increases with aging. However, the lack of BBB alteration in CDS dogs may be related to the absence of mature plaques, or to LRP1 and RAGE modifications in their function of $A \beta$ clearance [57-59]. In any case, with immunization, the BBB active $A \beta$ removal would increase and facilitate cognitive improvement.

The $v 3$ vaccine antigen builds a boost of antibodies, together with the possibility of a Bcell response by the C-A $\beta$ epitope [60]. Irregular familiar feeding habits are considered the main cause of the dog higher phosphatase alkaline levels because of its role in the digestion and absorption of fats in the intestinal tract [61] and cannot be related to the immunization. The risk of an inflammatory response was also fully discarded by the clinical follow-up of all animals and the normality of the frequent plasma and CSF analyses.

\section{CONCLUSIONS}

In conclusion, we have designed and validated in old dogs with graded cognitive dysfunction and a weak immune system the efficacy and security of a new vaccine considered a good candidate for human AD prevention and treatment. This study also confirms familiar dogs as a good natural model of $A D$, with the aim of developing innovative and reliable therapies. In these animals, the behavioral, CSF and plasma studies are rapid and easy to perform, and allow to decipher the intrinsic mechanisms involved in $A \beta$ physiopathology. This will shed light on our understanding of human amyloidosis. 


\section{ABBREVIATIONS}

ag-ab = antigen-antibody

$\mathrm{AC}=$ Adult Control

$\mathrm{AP}=$ Alkaline Phosphatase

CDS $=$ Cognitive dysfunction syndrome

CSF $=$ Cerebrospinal fluid

EDTA = Ethylenediaminetetraacetic acid

i.v = intravenously

Qalb = Albumin quotient

LCD = light cognitive deficit

$\mathrm{OC}=$ Old Control

s.c $=$ subcutaneously

SCD $=$ severe cognitive deficit 


\section{DISCLOSURE STATEMENT}

M.J.R., M.P and N.M. hold an EU patent (No. WO2010/012749) exploited by Medivet

Pharma, s.l. and hold shares of the company. The other authors report no disclosure.

\section{ACKNOWLEDGEMENTS}

The study was supported by the Centre for Industrial Technological Development (NEOTEC Initiative) Ministerio de Ciencia e Innovación, Spain. Research by NM and MJR work was supported by the grants SAF2008-01902 and IPT-010000-2010-35 from the Ministerio de Ciencia e Innovación, and by the 2009 SGR1380 grant from the Generalitat de Catalunya, Spain. We thank the Ars Veterinaria Hospital, Barcelona, Spain, for their help in the dog clinical assessment.

\section{REFERENCES}

[1] Ballard C, Gauthier S, Corbett A, Brayne C, Aarsland D, Jones E. Alzheimer'sdisease. Lancet 377, 1019-1031 (2011).

[2] Hardy J, Selkoe DJ. The Amyloid Hypothesis of Alzheimer's Disease: Progress and Problems on the Road to Therapeutics. Science 297, $353-356$ (2002).

[3] Sánchez L, Madurga S, Pukala T, Vilaseca M, López-Iglesias C, Robinson CV, Giralt E, Carulla N. A 340 and $A \beta 42$ amyloid fibrils exhibit distinct molecular recycling properties. J. Am. Chem. Soc 133, 6505-6508 (2011).

[4] Mucke L, Masliah E, Yu G-Q, Mallory M, Rockenstein EM, Tatsuno G, Hu K, Kholodenko D, Johnson-Wood K, McConlogue L. High-Level Neuronal Expression of A $\mathrm{B1}-42$ in Wild-Type Human Amyloid Protein Precursor Transgenic Mice: Synaptotoxicity without Plaque Formation. J Neurosci 20, $4050-4058$ (2000).

[5] Tomic JL, Pensalfini A, Head E, Glabe CG. Soluble fibrillar oligomer levels are elevated in Alzheimer's disease brain and correlate with cognitive dysfunction. Neurobiol. Dis 35, 352-358 (2009).

[6] Crews L, Masliah E. Molecular mechanisms of neurodegeneration in Alzheimer's disease. Hum. Mol. Genet 19, R12-20 (2010).

[7] Janus C, Pearson J, McLaurin J, Mathews PM, Jiang Y, Schmidt SD, Chishti MA, Horne P, Heslin D, French J, Mount HTJ, Nixon RA, Mercken M, Bergeron C, Fraser PE, St George-Hyslop P, Westaway D. Abeta peptide immunization reduces behavioural impairment and plaques in a model of Alzheimer's disease. Nature 408, 979-982 (2000).

[8] Morgan D, Diamond DM, Gottschall PE, Ugen KE, Dickey C, Hardy J, Duff K, 
Jantzen P, DiCarlo G, Wilcock D, Connor K, Hatcher J, Hope C, Gordon M, Arendash GW. Abeta peptide vaccination prevents memory loss in an animal model of Alzheimer's disease. Nature 408, 982-985 (2000).

[9] Ethell DW, Shippy D, Cao C, Cracchiolo JR, Runfeldt M, Blake B, Arendash GW. Abeta-specific T-cells reverse cognitive decline and synaptic loss in Alzheimer's mice. Neurobiol Disease 23, 351-361 (2006).

[10] Boche D, Denham N, Holmes C, Nicoll JAR. Neuropathology after active A $\beta 42$ immunotherapy: implications for Alzheimer's disease pathogenesis. Acta Neuropathol 120, 369-384 (2010).

[11] Cribbs DH, Ghochikyan A, Vasilevko V, Tran M, Petrushina I, Sadzikava N, Babikyan D, Kesslak P, Kieber-Emmons T, Cotman CW, Agadjanyan MG. Adjuvant-dependent modulation of Th1 and Th2 responses to immunization with beta-amyloid. Int. Immunol. 15, 505-514 (2003).

[12] Axelsen TV, Holm A, Christiansen G, Birkelund S. Identification of the shortest Abeta-peptide generating highly specific antibodies against the C-terminal end of amyloid-[beta]42. Vaccine 29, 3260-3269 (2011).

[13] Bosch MN, Pugliese M, Gimeno-Bayón J, Rodríguez MJ, Mahy N. Dogs with Cognitive Dysfunction Syndrome: A Natural Model of Alzheimer's Disease. Curr Alzheimer Res (2011).

[14] Head E, Pop V, Sarsoza F, Kayed R, Beckett TL, Studzinski CM, Tomic JL, Glabe CG, Murphy MP. Amyloid- $\beta$ Peptide and Oligomers in the Brain and Cerebrospinal Fluid of Aged Canines. J. Alzheimer's Dis. 20, 637-646 (2010).

[15] Ruehl WW, Bruyette DS, DePaoli A, Cotman CW, Head E, Milgram NW, Cummings BJ. Canine cognitive dysfunction as a model for human age-related cognitive decline, dementia and Alzheimer's disease: clinical presentation, cognitive testing, pathology and response to 1-deprenyl therapy. Prog. Brain Res 106, 217-225 (1995).

[16] Russell MJ, Bobik M, White RG, Hou Y, Benjamin SA, Geddes JW. Age-specific onset of beta-amyloid in beagle brains. Neurobiol. Aging 17, 269-273(1996).

[17] Pugliese M, Carrasco JL, Geloso MC, Mascort J, Michetti F, Mahy N. Y. aminobutyric acidergic interneuron vulnerability to aging in canine prefrontal cortex. J. Neurosci. Res. 77, 913-920 (2004).

[18] Carter MD, Simms GA, Weaver DF. The development of new therapeutics for Alzheimer's disease. Clin. Pharmacol. Ther 88, 475-486 (2010).

[19] Cotman CW, Head E. The Canine (Dog) Model of Human Aging and Disease: Dietary, Environmental and Immunotherapy Approaches. J Alzheimer's Dis 15, 685-707 (2008).

[20] Rofina JE, van Ederen AM, Toussaint MJM, Secreve M, van der Spek A, van der Meer I, Van Eerdenburg FJCM, Gruys E. Cognitive disturbances in old dogs suffering from the canine counterpart of Alzheimer's disease. Brain Research 1069, 216-226 (2006).

[21] Pugliese M, Carrasco JL, Andrade C, Mas E, Mascort J, Mahy N. Severe cognitive impairment correlates with higher cerebrospinal fluid levels of lactate and pyruvate in a canine model of senile dementia. Prog NeuroPsychopharmacol Biol Psychiatry 29, 603-610 (2005).

[22] Head E, Pop V, Vasilevko V, Hill M, Saing T, Sarsoza F, Nistor M, Christie L-A, Milton S, Glabe C, Barrett E, Cribbs D. A Two-Year Study with Fibrillar \{beta\}- 
Amyloid Abeta Immunization in Aged Canines: Effects on Cognitive Function and Brain Abeta. J. Neurosci. 28, 3555-3566 (2008).

[23] Vasilevko V, Pop V, Kim HJ, Saing T, Glabe CC, Milton S, Barrett EG, Cotman $\mathrm{CW}$, Cribbs $\mathrm{DH}$, Head E. Linear and conformation specific antibodies in aged beagles after prolonged vaccination with aggregated Abeta. Neurobiology of Disease 39, 301-310 (2010).

[24] Pugliese M, Geloso MC, Carrasco JL, Mascort J, Michetti F, Mahy N. Canine cognitive deficit correlates with diffuse plaque maturation and $\mathrm{S} 100 \beta(-)$ astrocytosis but not with insulin cerebrospinal fluid level. Acta Neuropathol 111, 519-528 (2006).

[25] Araujo JA, Greig NH, Ingram DK, Sandin J, de Rivera C, Milgram NW. Cholinesterase Inhibitors Improve Both Memory and Complex Learning in Aged Beagle Dogs. J Alzheimers Dis (2011).

[26] Milgram NW. Cognitive experience and its effect on age-dependent cognitive decline in beagle dogs. Neurochem. Res 28, 1677-1682 (2003).

[27] Braak H, Braak E. Demonstration of amyloid deposits and neurofibrillary changes in whole brain sections. Brain Pathol 1, 213-216 (1991).

[28] Tibbling $G$, Link $H$, Ohman S. Principles of albumin and IgG analyses in neurological disorders. I. Establishment of reference values. Scand. J. Clin. Lab. Invest 37, 385-390 (1977).

[29] Pugliese M, Mascort J, Mahy N, Ferrer I. Diffuse beta-amyloid plaques and hyperphosphorylated tau are unrelated processes in aged dogs with behavioral deficits. Acta Neuropathol 112, 175-183 (2006).

[30] Skoumalova A, Rofina J, Schwippelova Z, Gruys E, Wilhelm J. The role of free radicals in canine counterpart of senile dementia of the Alzheimer type. Exp. Gerontol 38, 711-719 (2003).

[31] Vajdovich P, Gaál T, Szilágyi A, Harnos A. Changes in some red blood cell and clinical laboratory parameters in young and old Beagle dogs. Vet. Res. Commun. 21, 463-470 (1997).

[32] Pomara N, Willoughby LM, Sidtis JJ, Mehta PD. Selective reductions in plasma Abeta 1-42 in healthy elderly subjects during longitudinal follow-up: a preliminary report. Am J Geriatr Psychiatry 13, 914-917 (2005).

[33] van Oijen M, Hofman A, Soares HD, Koudstaal PJ, Breteler MMB.Plasma Abeta(1-40) and Abeta(1-42) and the risk of dementia: a prospective casecohort study. Lancet Neurol 5, 655-660(2006).

[34] González-Martínez A, Rosado B, Pesini P, Suárez M-L, Santamarina G, García-Belenguer S, Villegas A, Monleón I, Sarasa M. Plasma $\beta$-amyloid peptides in canine aging and cognitive dysfunction as a model of Alzheimer's disease. Exp Gerontol (2011).

[35] Morita T, Mizutani Y, Sawada M, Shimada A. Immunohistochemical and ultrastructural findings related to the blood--brain barrier in the blood vessels of the cerebral white matter in aged dogs. J. Comp. Pathol. 133, 14-22 (2005).

[36] Popescu BO, Toescu EC, Popescu LM, Bajenaru O, Muresanu DF, Schultzberg $\mathrm{M}$, Bogdanovic N. Blood-brain-barrier alterations in ageing and dementia. $J$ Neurological Sciences 283, 99-106 (2009).

[37] Blennow K, Wallin A, Fredman P, Karlsson I, Gottfries CG, Svennerholm L. Blood-brain barrier disturbance in patients with Alzheimer's disease is related to 
vascular factors. Acta Neurol. Scand. 81, 323-326 (1990).

[38] Tipold A, Pfister $\mathrm{H}$, Zurbriggen A, Vandevelde $\mathrm{M}$ Intrathecal synthesis of major immunoglobulin classes in inflammatory diseases of the canine CNS. Vet. Immunol. Immunopathol 42, 149-159 (1994).

[39] Hampel H, Kötter HU, Padberg F, Körschenhausen DA, Möller HJ. Oligoclonal Bands and Blood-Cerebrospinal-Fluid Barrier Dysfunction in a subset of Patients with Alzheimer Disease: Comparison with Vascular Dementia, Major Depression, and Multiple Sclerosis. Alzheimer Dis \& Associated Disorders 13, (1999).

[40] Webb AA, Muir GD. The blood-brain barrier and its role in inflammation. J. Vet. Intern. Med. 14, 399-411 (2000).

[41] Kleine TO, Hackler R, Zöfel P. Age-related alterations of the blood-brain-barrier permeability to protein molecules of different size. Z Gerontol 26, 256-259 (1993).

[42] Prodan Cl, Ross ED, Stoner JA, Cowan LD, Vincent AS, Dale GL. Coatedplatelet levels and progression from mild cognitive impairment to Alzheimer disease. Neurology 76, 247-252 (2011).

[43] Strozyk D, Blennow K, White LR, Launer LJ. CSF Abeta 42 levels correlate with amyloid-neuropathology in a population-based autopsy study. Neurology 60, 652-656 (2003).

[44] Fagan AM, Mintun MA, Mach RH, Lee S-Y, Dence CS, Shah AR, LaRossa GN, Spinner ML, Klunk WE, Mathis CA, DeKosky ST, Morris JC, Holtzman DM. Inverse relation between in vivo amyloid imaging load and cerebrospinal fluid Abeta42 in humans. Ann. Neurol. 59, 512-519 (2006).

[45] Rami L, Fortea J, Bosch B, Solé-Padullés C, Lladó A, Iranzo A, Sánchez-Valle $\mathrm{R}$, Molinuevo JL. Cerebrospinal Fluid Biomarkers and Memory Present Distinct Associations along the Continuum from Healthy Subjects to AD Patients. $J$ Alzheimer's Dis 23, 319-326 (2011).

[46] Tekirian TL, Cole GM, Russell MJ, Yang F, Wekstein DR, Patel E, Snowdon DA, Markesbery WR, Geddes JW. Carboxy terminal of beta-amyloid deposits in aged human, canine, and polar bear brains. Neurobiol. Aging 17, 249-257 (1996).

[47] Lemere CA, Blusztajn JK, Yamaguchi H, Wisniewski T, Saido TC, Selkoe DJ. Sequence of deposition of heterogeneous amyloid beta-peptides and APO E in Down syndrome: implications for initial events in amyloid plaque formation. Neurobiol. Dis. 3, 16-32 (1996).

[48] Miyawaki K, Nakayama H, Matsuno S, Tamaoka A, Doi K. Three-dimensional and fractal analyses of assemblies of amyloid beta protein subtypes Abeta40 and Abeta42(43) in canine senile plaques. Acta Neuropathol 103, 228-236 (2002).

[49] Irvine GB, El-Agnaf OM, Shankar GM, Walsh DM. Protein aggregation in the brain: the molecular basis for Alzheimer's and Parkinson's diseases. Mol. Med. 14, 451-464 (2008).

[50] Burns EA, Lum LG, L'Hommedieu G, Goodwin JS. Specific humoral immunity in the elderly: in vivo and in vitro response to vaccination. $J$ Gerontol 48, B231236 (1993).

[51] Schnabel J Vaccines: Chasing the dream. Nature 475, S18-S19 (2011). 
[52] Lemere CA, Masliah E. Can Alzheimer disease be prevented by amyloid-beta immunotherapy? Nat Rev Neurol 6, 108-119 (2010).

[53] Banks WA, Terrell B, Farr SA, Robinson SM, Nonaka N, Morley JE Passage of amyloid $\beta$ protein antibody across the blood-brain barrier in a mouse model of Alzheimer's disease. Peptides 23, 2223-2226 (2002).

[54] Gray AJ, Sakaguchi G, Shiratori C, Becker AG, LaFrancois J, Aisen PS, Duff K, Matsuoka Y. Antibody against C-terminal Abeta selectively elevates plasma Abeta. Neuroreport 18, 293-296 (2007).

[55] Miller DL, Potempska A, Mehta PD. Humoral immune responses to peptides derived from the $\beta$-amyloid peptide C-terminal sequence. Amyloid 14, 39-50 (2007).

[56] von Bubnoff A. Vaccines to antibodies: grow up! IAVI Rep 14, 4-9 (2010).

[57] Zhang Y, Lee DHS. Sink Hypothesis and Therapeutic Strategies for Attenuating A $\beta$ Levels. The Neuroscientist 17, $163-173$ (2011).

[58] Deane R, Bell R, Sagare A, Zlokovic B. Clearance of amyloid- $\beta$ peptide across the blood-brain barrier: Implication for therapies in Alzheimer's disease. CNS Neurol Disord Drug Targets 8, 16-30 (2009).

[59] Bachmeier CJ, Beaulieu-Abdelahad D, Mullan MJ, Paris D. Epitope-dependent effects of beta-amyloid antibodies on beta-amyloid clearance in an in vitro model of the blood-brain barrier. Microcirculation (2011).

[60] Axelsen TV, Holm A, Birkelund S, Christiansen G, Ploug M, Holm IE. Specific recognition of the $\mathrm{C}$-terminal end of $\mathrm{A} \beta 42$ by a high affinity monoclonal antibody. Molecular Immunology 46, 2267-2273 (2009).

[61] Hatayama K, Nishihara Y, Kimura S, Goto K, Nakamura D, Wakita A, et al. Serum alkaline phosphatase isoenzymes in laboratory beagle dogs detected by polyacrylamide-gel disk electrophoresis. J Toxicol Sci.36, 653-660 (2011). 


\section{FIGURE LEGENDS}

Fig. 1 Schematic timeline of canine immunization study. Horizontal arrow indicates the immunization period during which 6 doses of v3 vaccine or were subcutaneously injected. Vertical arrows indicate the cognitive evaluation days and the CSF and serum extraction days. The same immunization period and blood extraction protocol was used in the study performed in rabbits to select the best vaccine composition.

Fig. 2 Plasma $A \beta_{40}$ and CSF $A \beta_{40}$ and $A \beta_{42}$ levels in control (AC and $O C$ ) dogs and CDS dogs (LCD and SCD). In LCD dogs, plasma $A \beta_{40}$ levels $(A)$ are different $(p=0.029)$ and also CSF $A \beta_{42}$ levels (C) $(p=0.018)$. Two subgroups are observed in this LCD group: LCD1, the dogs with higher plasma $A \beta_{40}$ levels $(p=0.009)$ and $L C D 2$, the dogs with higher CSF $A \beta_{42}$ levels $(p=0.018)$. CSF $A \beta_{40}$ level is similar in control and CDS dogs (B).

Fig. 3 Anti-A $\beta_{40}$ levels in $v 1, v 2$ and $v 3$ immunized rabbits during the immunization period (A) and cognitive changes of $v 3$ immunized CDS dogs (B). Anti-A $\beta_{40}$ lgG levels in immunized rabbits reach a peak at day 51 . Rabbits immunized with the v3 vaccine, present higher antibody levels. The dog cognitive changes during the immunization study was evaluated by the veterinarian with a validated Cognitive test performed at days $0,31,51$, and 131 . At day 31 , significant changes were already detected in all immunized CDS dogs $\left(p={ }^{*} 0.027\right)(B)$.

Fig. 4 Plasma $A \beta_{40}, C S F A \beta_{40}$ and $A \beta_{42}$, and antibody levels during the whole study. $A$ tendency to increase of plasma $A \beta_{40}$ in $A C$ and CDS dogs $(A)$, is observed but only a marked decrease of CSF $A \beta_{40}$ and $A \beta_{42}$ levels in CDS dogs after the immunization period $\left({ }^{*} p=0.049\right.$ for $\left.A \beta_{42}\right)(B, C)$. The ratio between those levels is only increased in the LCD dogs when we compare the groups at days 0 and $51,(\mathrm{H})$. Anti-A $\beta_{40} \lg G$ is detected in serum and CSF at day 30 after the first boost (levels over $0.24 n m)(E-F)$. In $A C$ dogs the highest level is observed at day $51\left({ }^{\#} p=0.0042\right.$ vs pre-immune levels; 
${ }^{*} p=0.0079$ vs placebo levels) $(E)$ and in CDS dogs at day $71\left({ }^{\#} p=0.0078\right.$ vs preimmune levels; ( ${ }^{*} p=0.0022$ vs placebo levels). CSF Anti-A $\beta_{40} \lg G$ is detected in all dogs with significant differences at day 31 in $A C$ dogs $(\# p=0.0042$ vs pre-immune values; ${ }^{*} p=0.0078$ vs placebo values) $(F)$. Serum and CSF antibodies are positively correlated in $A C$ and CDS dogs $(G)$. However, plasma $A \beta_{40}$ and plasma anti-A $\beta_{40}$ IgG levels are only correlated in CDS dogs, (I).

Fig. 5 Detection of $A \beta$ plaques in $A D$ human brain with purified antibodies from immunized rabbits and dogs. Micrographs at $5 x$ and $40 x$. Antibodies from v1 $\left(A \beta_{40}\right)$ or v3 $\left(A \beta_{40}+A \beta_{x-40}\right)$ immunized rabbits detect diffuse and core plaques (B, D). Antibodies from v2 $\left(A \beta_{x-40}\right)$ immunized rabbits only detect diffuse plaques $(C)$. Antibodies from v3 immunized dogs only detect diffuse plaques. Plaque detection with IgG from AC (F) or CDS dogs $(G)$ is similar. Positive control with a commercial antibody $(A, E)$. 
Figures

Fig.1

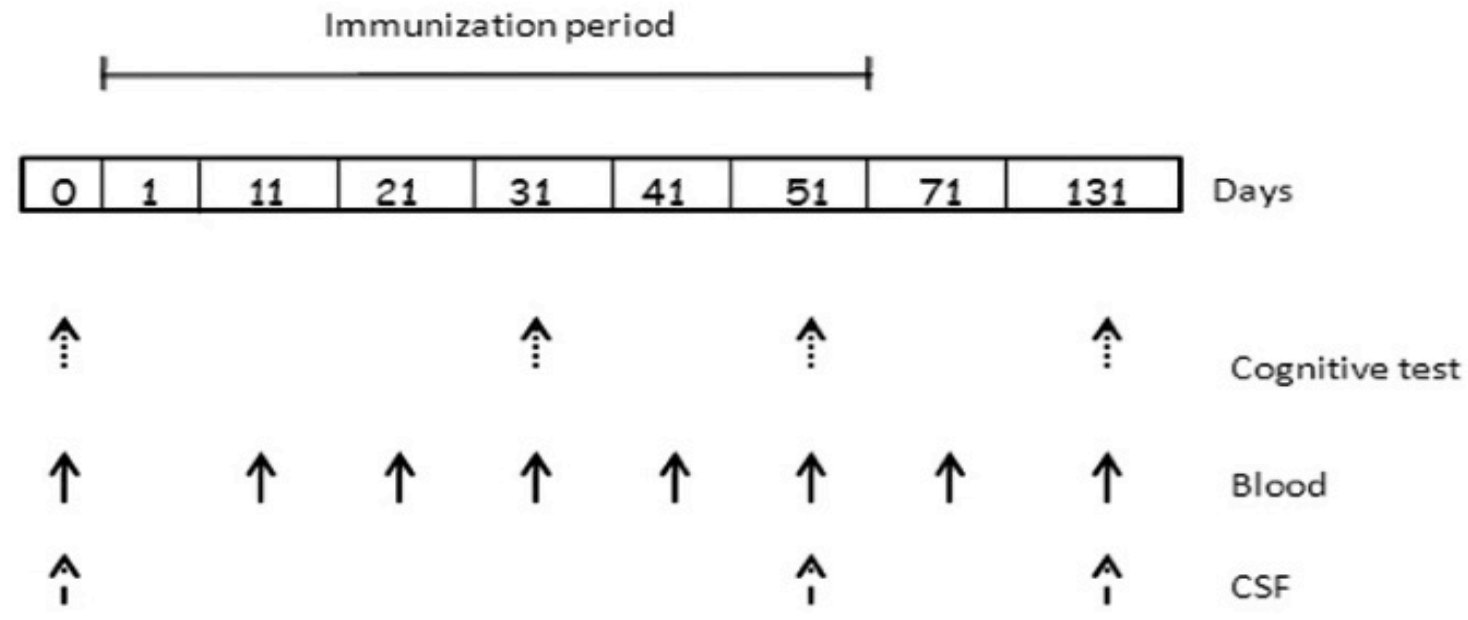


Fig.2

A.

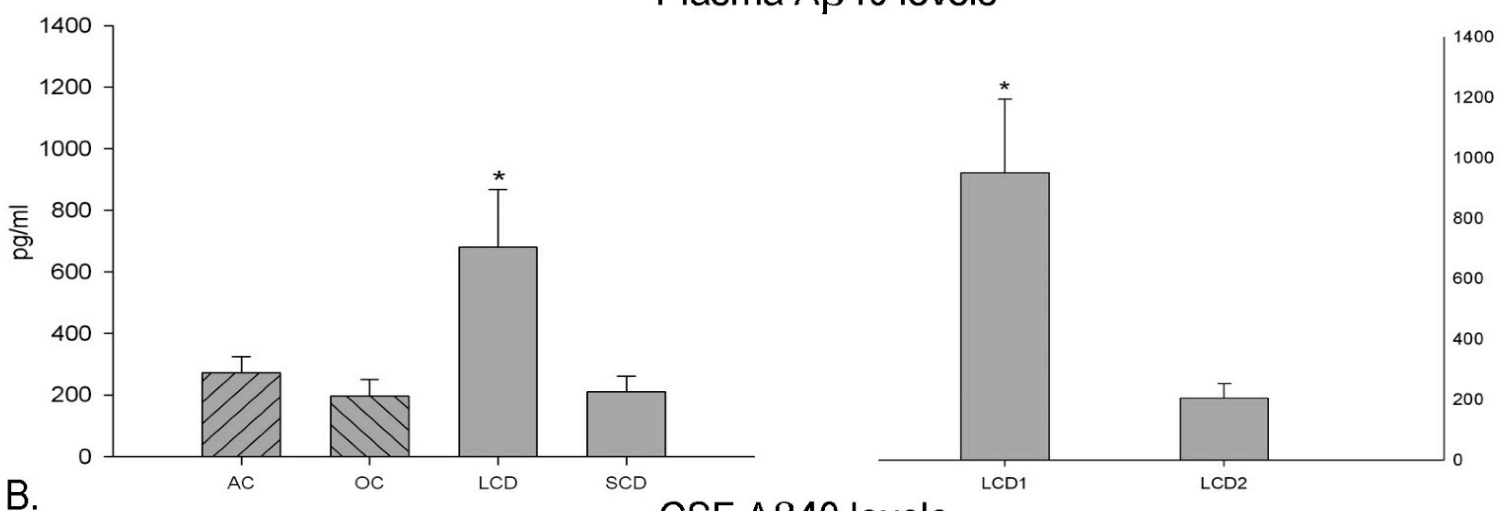

B.

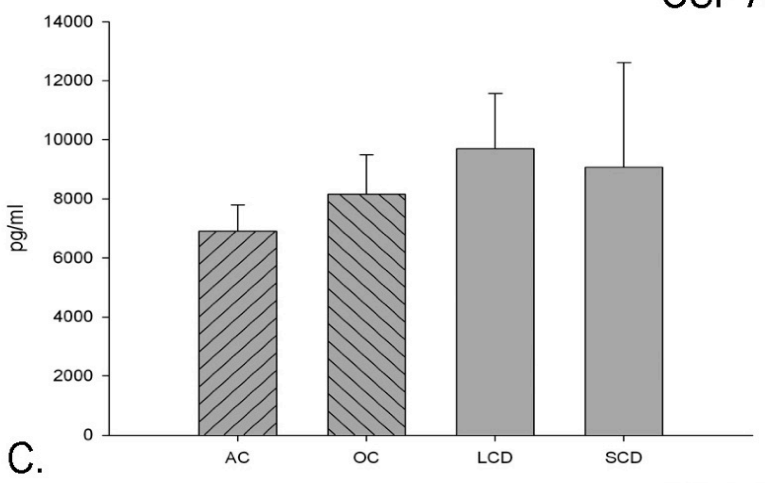

${ }_{1400} \quad$ CSF A 342 levels
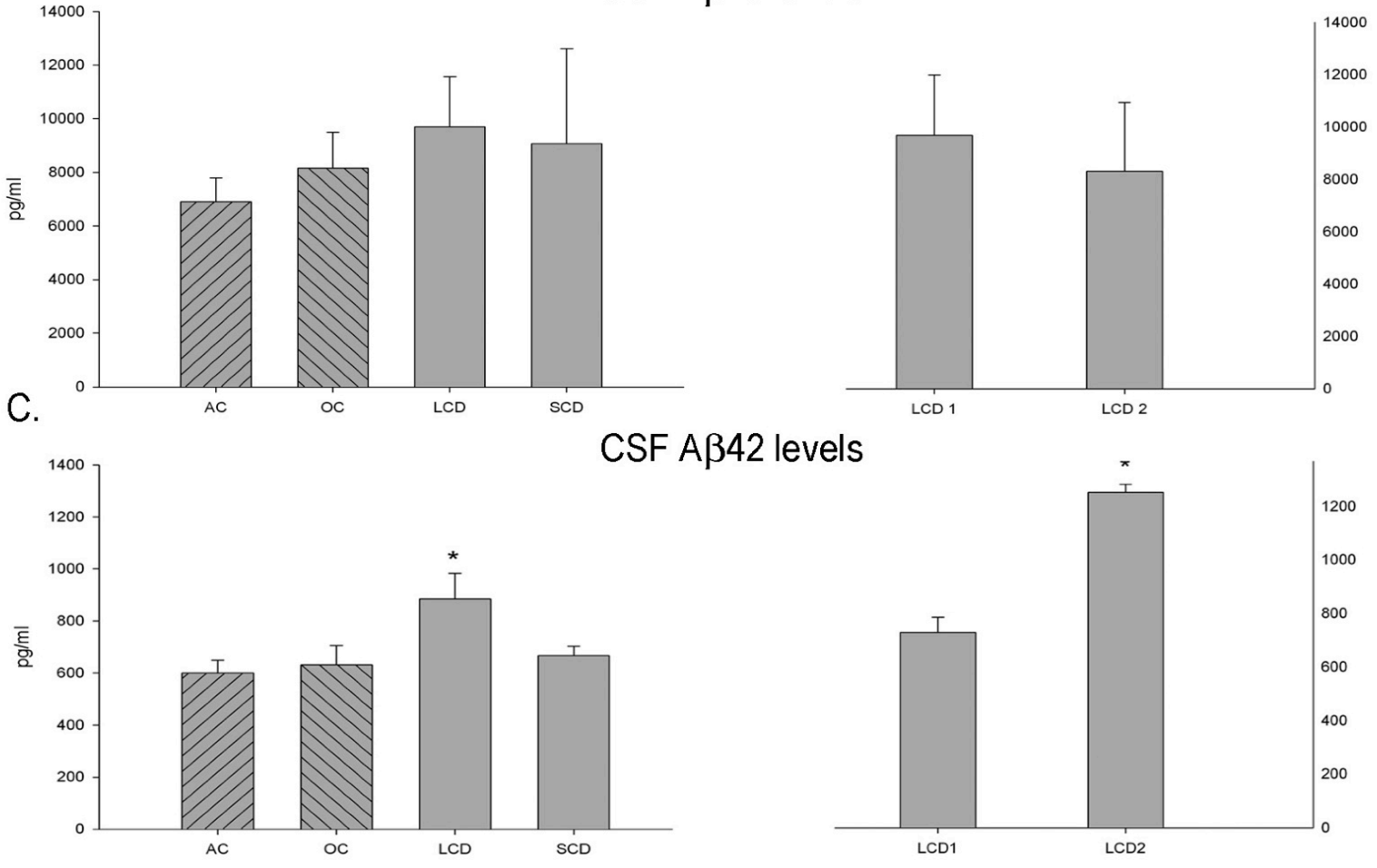

D.

[CSF albumin]/[Serum albumin]

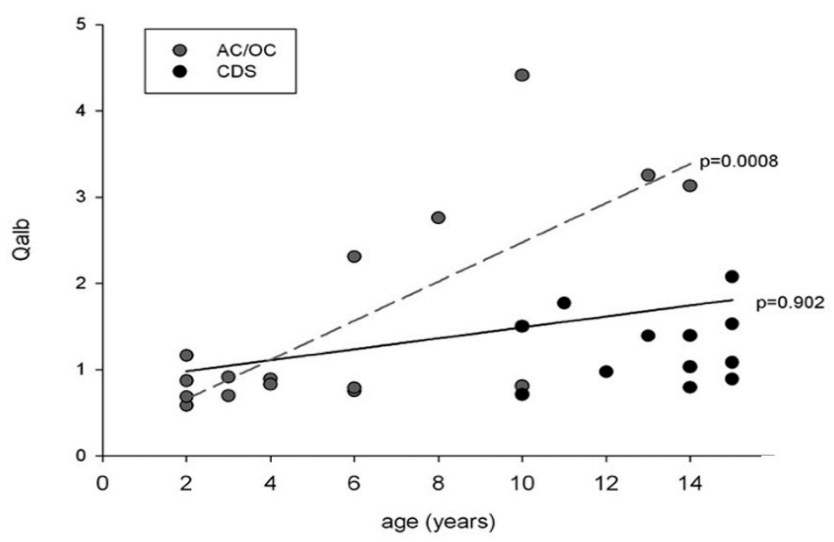


Fig.3

\section{A. Anti-A $\beta 40$ IgG in rabbit}

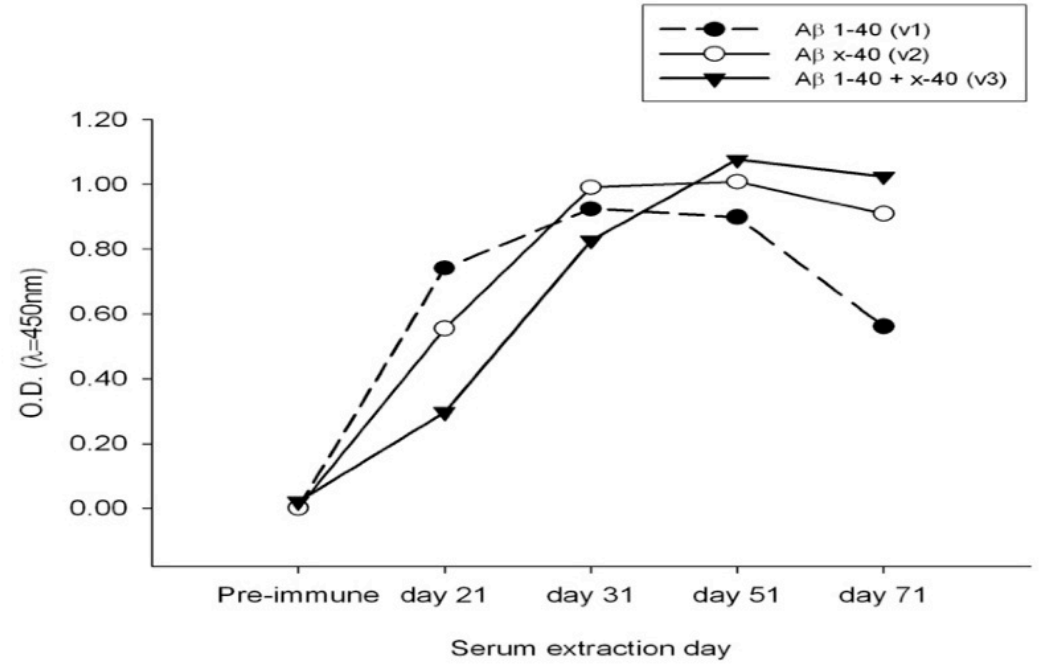

\section{B. Cognitive test score}

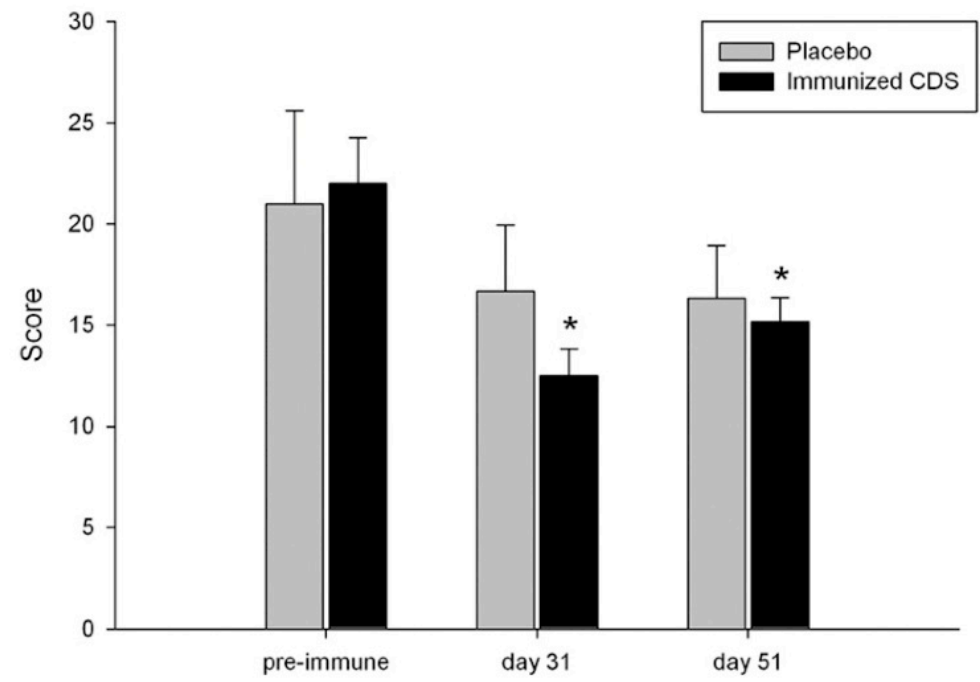


Fig.4
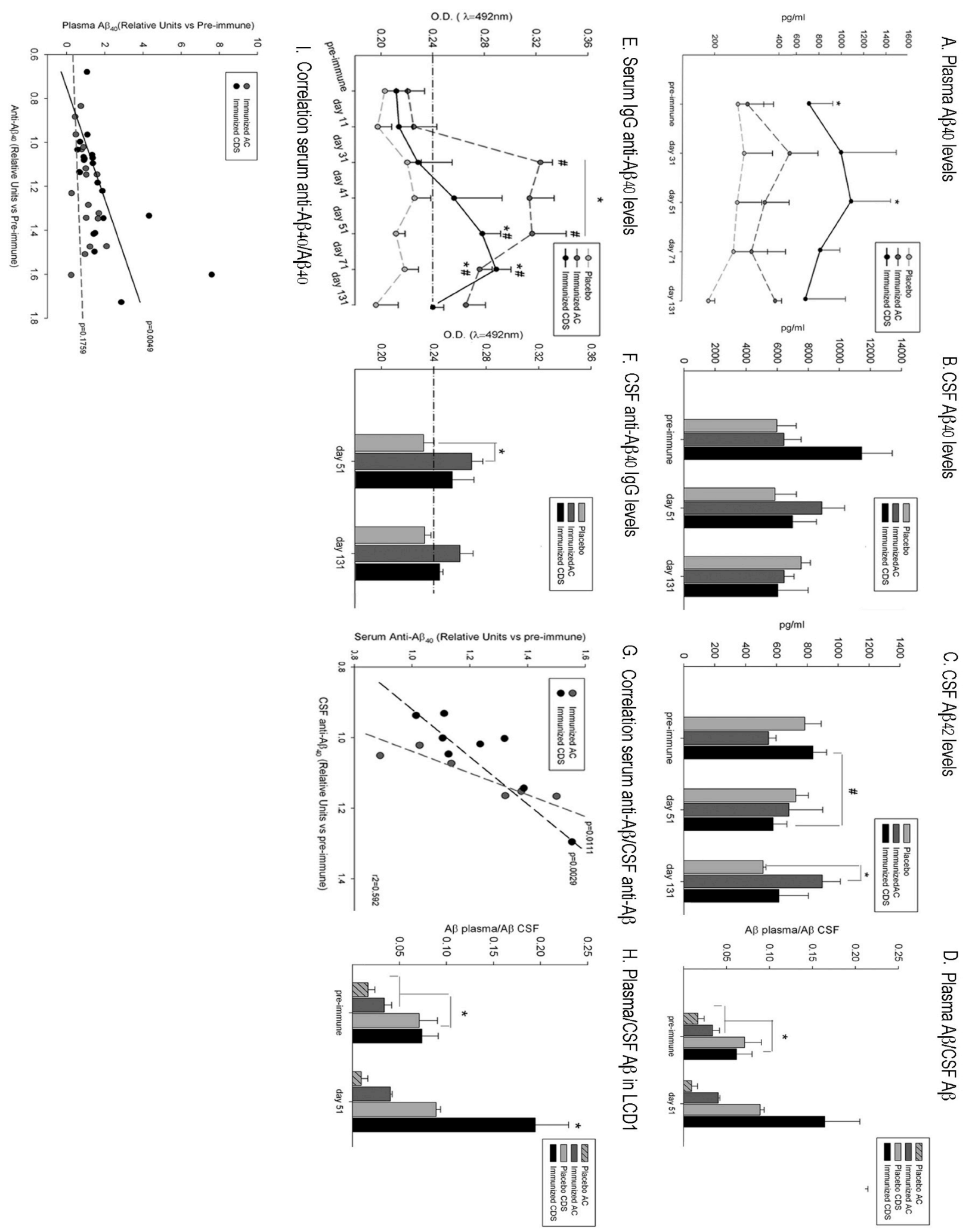
Fig. 5
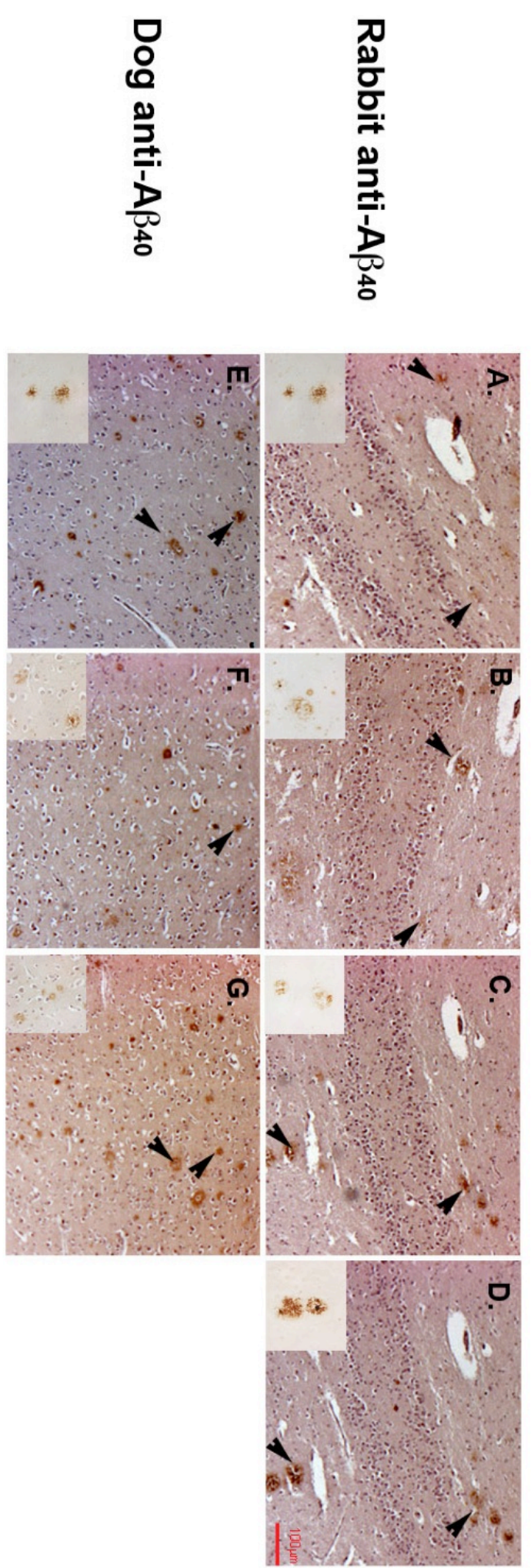
TABLES

Table 1 Diversity of the dogs

\begin{tabular}{|c|c|c|c|c|c|}
\hline ID & Breed & Sex & Age & $\begin{array}{l}\text { Screening } \\
\text { group }\end{array}$ & $\begin{array}{l}\text { Immunization } \\
\text { group }\end{array}$ \\
\hline 1 & Housed beagle dog & Male & 2 & $A C$ & Immunized AC \\
\hline 2 & Housed beagle dog & Male & 2 & $A C$ & Immunized AC \\
\hline 3 & Housed beagle dog & Male & 3 & $A C$ & Immunized AC \\
\hline 4 & Housed beagle dog & Male & 4 & $A C$ & Immunized AC \\
\hline 5 & Housed beagle dog & Male & 4 & $A C$ & Immunized AC \\
\hline 6 & Housed beagle dog & Male & 6 & $A C$ & Immunized AC \\
\hline 7 & Housed beagle dog & Male & 4 & $\mathrm{AC}$ & Placebo \\
\hline 8 & Housed beagle dog & Male & 2 & $\mathrm{AC}$ & Placebo \\
\hline 9 & Housed beagle dog & Male & 2 & $A C$ & Placebo \\
\hline 10 & Housed beagle dog & Male & 3 & $A C$ & \\
\hline 11 & Housed beagle dog & Male & 6 & $A C$ & \\
\hline 12 & Housed beagle dog & Male & 8 & $\mathrm{OC}$ & \\
\hline 13 & Belgian Shepherd dog & Female & 6 & $\mathrm{AC}$ & \\
\hline 14 & Rottweiler & Female & 7 & $A C$ & \\
\hline 15 & Mixed breed & Female & 6 & $A C$ & \\
\hline 16 & Mixed breed & Male & 10 & $\mathrm{OC}$ & \\
\hline 17 & Mixed breed & Female & 10 & $\mathrm{OC}$ & \\
\hline 18 & Mixed breed & Male & 12 & $\mathrm{OC}$ & \\
\hline 19 & Catalan shepherd breed & Male & 12 & $\mathrm{OC}$ & \\
\hline 20 & Beagle & Male & 13 & $\mathrm{OC}$ & \\
\hline
\end{tabular}




\begin{tabular}{|c|c|c|c|c|c|}
\hline 21 & Mixed breed & Male & 13 & $\mathrm{OC}$ & \\
\hline 22 & Catalan shepherd dogs & Male & 14 & $\mathrm{OC}$ & \\
\hline 23 & Mixed breed & Female & 14 & LCD & \\
\hline 24 & Kurzhaar & Female & 12 & LCD & \\
\hline 25 & Golden Retriever & Female & 11 & LCD & Placebo \\
\hline 26 & Mixed & Female & 14 & LCD & Placebo \\
\hline 27 & Catalan shepherd & Male & 15 & LCD & Immunized CDS \\
\hline 28 & Mixed breed & Male & 15 & LCD & Immunized CDS \\
\hline 29 & Boxer & Male & 10 & LCD & Immunized CDS \\
\hline 30 & Mixed breed & Female & 13 & LCD & Immunized CDS \\
\hline 31 & Mixed breed & Male & 14 & LCD & Immunized CDS \\
\hline 32 & Beagle & Male & 14 & LCD & Immunized CDS \\
\hline 33 & Mixed breed & Male & 15 & SCD & Placebo \\
\hline 34 & Golden Retriever & Female & 15 & SCD & Immunized CDS \\
\hline 35 & Mixed breed & Female & 18 & SCD & Immunized CDS \\
\hline 36 & Mixed breed & Male & 15 & SCD & Immunized CDS \\
\hline
\end{tabular}

12 housed beagle and 24 familiar dogs were used in the study. In this last group, 14 animals identified as CDS by their neurological records and cognitive test were subdivided into two groups according to their total score: 10 dogs identified with Light Cognitive Dementia (LCD) and 4 with Severe Cognitive Dementia (SCD), (See details in Table1). For their characterization, they were matched with Adult Control $(A C, n=14)$ and Old Control dogs $(\mathrm{OC}, \mathrm{n}=8)$. For the Immunization study $12 \mathrm{CDS}$ dogs and 9 housed beagle dogs were included, and 9 CDS (Immunized CDS) and 6 housed beagle dogs (Immunized AC) received the $\sqrt{3}$ vaccine. 3 CDS dogs and $3 \mathrm{AC}$ received Saline solution + Alum (Placebo group). 
Table 2. Cognitive Test

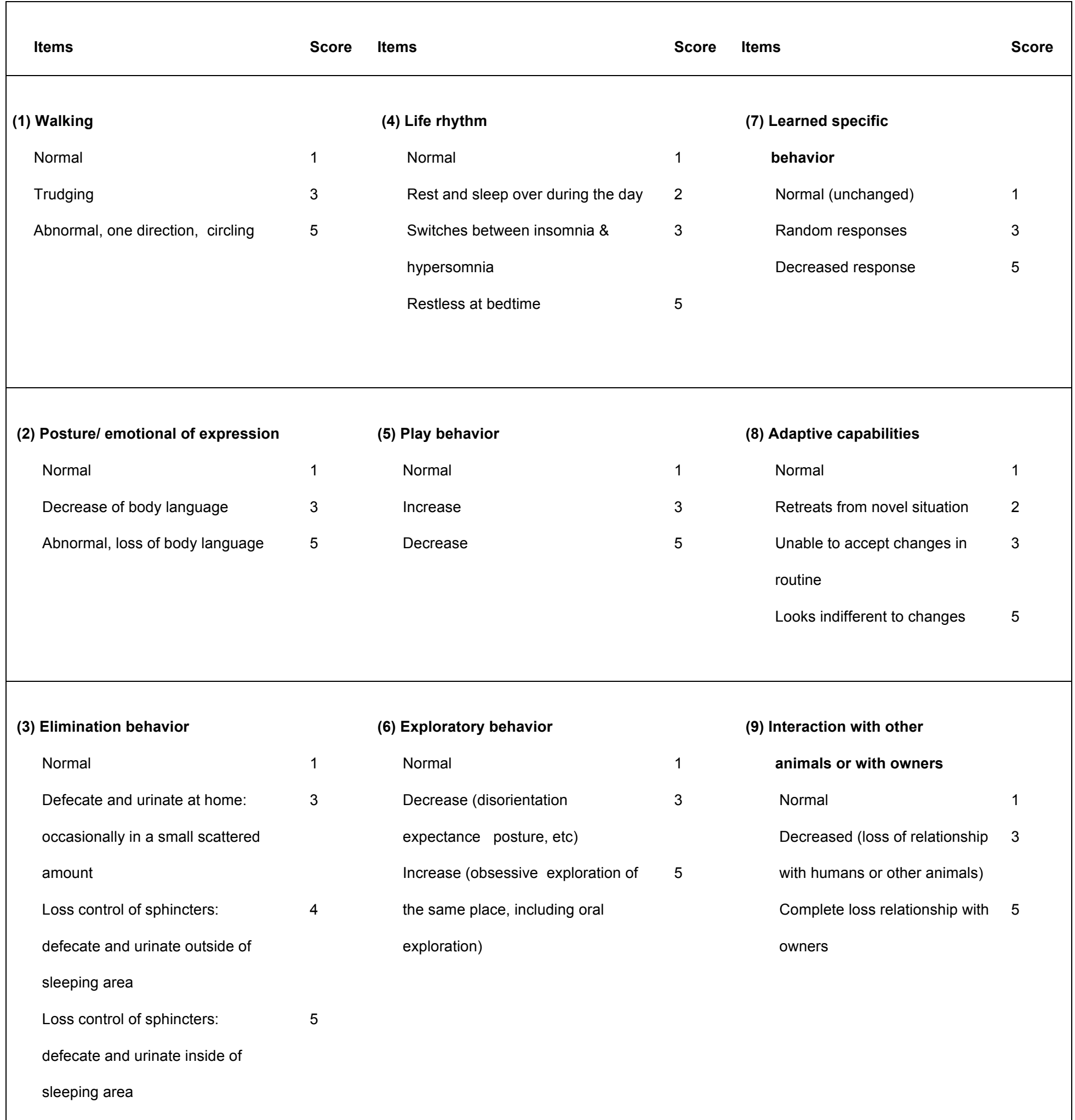

Total score in the 9 items test: $<12=$ normal; $12-26=$ light cognitive deficits SCD; $>26=$ severe cognitive 
Table 3. Hematological and biochemistry parameters during immunization study

\begin{tabular}{|c|c|c|c|c|}
\hline Hematological parameters & Placebo & Immunized AC & Immunized CDS & Range \\
\hline White blood cells & $6.49 \pm 0.68-10.88 \pm 1.58$ & $6.08 \pm 0.99-11.10 \pm 0.416$ & $6.99 \pm 1.15-0.86 \pm 1.26$ & $5.05-16.76$ \\
\hline Lymphocytes & $1.30 \pm 0.15-2.20 \pm 0.66$ & $1.05 \pm 0.16-2.33 \pm 0.74$ & $1.07 \pm 0.21-2.30 \pm 0.54$ & $1.05-5.10$ \\
\hline Monocytes & $0.42 \pm 0.81-1.18 \pm 0.19$ & $0.45 \pm 0.11-0.98 \pm 0.15$ & $0.43 \pm 0.05-1.04 \pm 0.15$ & $0.16-1.12$ \\
\hline Neutrophils & $4.38 \pm 0.50-13.00 \pm 8.52$ & $4.21 \pm 0.52-8.06 \pm 0.13$ & $4.18 \pm 1.59-6.67 \pm 1.38$ & $2.95-11.64$ \\
\hline Eosinophil's & $0.22 \pm 0.05-0.37 \pm 0.10$ & $0.31 \pm 0.04-0.72 \pm 0.16$ & $0.19 \pm 0.08-0.43 \pm 0.11$ & $0.06-1.23$ \\
\hline Basophils & $0.02 \pm 0.004-0.06 \pm 0.01$ & $0.02 \pm 0.005-0.06 \pm 0.01$ & $0.02 \pm 0.006-0.05 \pm 0.01$ & $0.00-0.10$ \\
\hline Hematocrit & $46.88 \pm 2.51-48.83 \pm 1.07$ & $47.06 \pm 1.46-57.90 \pm 1.13$ & $41.27 \pm 4.73-47.82 \pm 6.57$ & $37.3-61.7$ \\
\hline Hemoglobin & $14.45 \pm 0.48-16.13 \pm 0.55$ & $14.96 \pm 0.41-18.63 \pm 0.41$ & $13.700 \pm 1.35-5.27 \pm 0.56$ & $13.1-20.5$ \\
\hline Reticulocytes & $29.86 \pm 8.71-42 \pm 4.80$ & $37.80 \pm 4.08-64.13 \pm 9.95$ & $29.81 \pm 4.49-43.41 \pm 7.93$ & $6.6-100.7$ \\
\hline Platelets & $178.33 \pm 31.07-381.25( \pm 84.86$ & $221.67 \pm 5.17-18.33 \pm 25.20$ & $285.50 \pm 40.77-343 \pm 41.51$ & $148-484$ \\
\hline
\end{tabular}




\begin{tabular}{|c|c|c|c|c|}
\hline $\begin{array}{l}\text { Biochemical } \\
\text { parameters }\end{array}$ & Placebo & Immunized AC & Immunized CDS & Range \\
\hline Alkaline Phosphatase (AP) & $105.33 \pm 6.32-238.83 \pm 48.01$ & $89.33 \pm 18.50-165.00 \pm 72.39$ & $403.71 \pm 136.59-760.71 \pm 256.45$ & $23-212$ \\
\hline $\begin{array}{l}\text { Glutamate Pyruvate } \\
\text { Transaminase (GPT) }\end{array}$ & $41.33 \pm 9.49-119.833 \pm 51.46$ & $39.67 \pm 9.82-80.67 \pm 18.80$ & $99.66 \pm 22.44-161.66 \pm 25.26$ & $0-100$ \\
\hline Creatinine & $0.793 \pm 0.11-1.10 \pm 0.07$ & $0.79 \pm 0.08-1.04 \pm 0.02$ & $0.87 \pm 0.11-1.13 \pm 0.15$ & $0.5-1.8$ \\
\hline Urea & $33.25 \pm 3.62-64.31 \pm 15.92$ & $24.43 \pm 3.76-58.5 \pm 3.77$ & $40.52 \pm 8.98-106.21 \pm 36.67$ & $18-60$ \\
\hline Total protein & $6.20 \pm 0.115-6.66 \pm 0.287$ & $5.90 \pm 0.06-6.80 \pm 0.15$ & $6.55 \pm 0.13-7.45 \pm 0.21$ & $5.2-8.2$ \\
\hline Glucose & $100.50 \pm 12.41-115.66 \pm 6.35$ & $98.00 \pm 10.01-128 \pm 6.50$ & $89.80 \pm 4.54-107.28 \pm 5.35$ & $74-143$ \\
\hline
\end{tabular}

Biochemical and hematological parameters measured during the immunization study with their minimum and maximum values ( \pm s.d.). Values in bold of alkaline phosphatase present significant differences in familiar dogs 